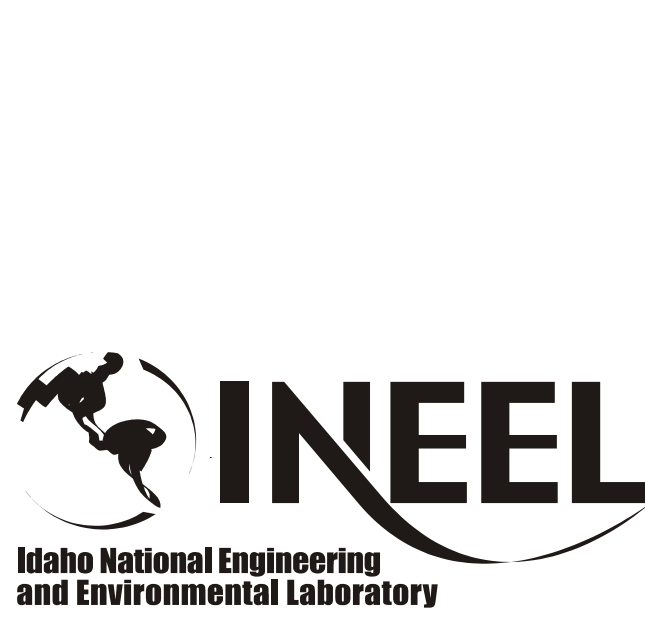

INEEL/CON-02-00055

PREPRINT

\title{
Long-Term Stewardship Science and Technology Requirements
}

\author{
J. McDonald \\ R. Nickelson
}

August 4, 2002 - August 8, 2002

\section{Spectrum 2002}

This is a preprint of a paper intended for publication in a journal or proceedings. Since changes may be made before publication, this preprint should not be cited or reproduced without permission of the author.

This document was prepared as a account of work sponsored by an agency of the United States Government. Neither the United States Government nor any agency thereof, or any of their employees, makes any warranty, expressed or implied, or assumes any legal liability or responsibility for any third party's use, or the results of such use, of any information, apparatus, product or process disclosed in this report, or represents that its use by such third party would not infringe privately owned rights. The views expressed in this paper are not necessarily those of the U.S. Government or the sponsoring agency. 


\title{
Long-Term Stewardship Science and Technology Requirements
}

\author{
Joan McDonald, P.E. \\ Reva Nickelson
}

\author{
Idaho National Engineering and Environmental Laboratory \\ Long-Term Stewardship Science and Technology Program \\ P.O. Box 1625, Idaho Falls, Idaho 83415-1625
}

\begin{abstract}
To ensure technology developed for long-term stewardship will meet existing requirements, a review of requirements was performed. In addition to identifying existing science and technology related requirements, gaps and conflicts of requirements were identified.
\end{abstract}

\section{INTRODUCTION}

Many of the United States' hazardous and radioactively contaminated waste sites will not be sufficiently remediated to allow unrestricted land use because funding and technology limitations preclude cleanup to pristine conditions. This means that after cleanup is completed, the Department of Energy will have long-term stewardship responsibilities to monitor and safeguard more than 100 sites that still contain residual contamination. Long-term stewardship encompasses all physical and institutional controls, institutions, information, and other mechanisms required to protect human health and the environment from the hazards remaining.

The Department of Energy Long-Term Stewardship National Program is in the early stages of development, so considerable planning is still required to identify all the specific roles and responsibilities, policies, and activities needed over the next few years to support the program's mission. The Idaho National Engineering and Environmental Laboratory was tasked with leading Science and Technology within the Long-Term Stewardship National Program. As part of that role, a task was undertaken to identify the existing science and technology related requirements, identify gaps and conflicts that exist, and make recommendations to the Department of Energy for future policy and guidance related to science and technology requirements for long-term stewardship. This work is summarized in this paper.

This science and technology requirements work directly supports another key aspect of the Long-Term Stewardship National Program - the Science and Technology Roadmap. Science and technology roadmapping is an effective way to identify and forecast critical technology development for increasing protection of human health and the environment, mitigating risks, and decreasing life-cycle costs. In the process of identifying technology development needs, it is important to include the requirements the technology must meet when applied in the field; failure to do so will render the technology useless. To increase the likelihood of success, this review of national requirements and policy applicable to science and technology applications in support of long-term stewardship operations was performed. As a result of the review, not only were national regulatory requirements identified, but gaps and conflicts were also identified, and a science and technology 
policy/guidance strategy was developed for the Department's consideration.

\section{WORK DESCRIPTION}

Review and identification of national science and technology requirements, standards, and policies were based on site types. Prior to entering long-term stewardship, sites will undergo some form of remediation and closure. The primary national regulations, laws, and policies that dictate remediation and closure vary by site types. The sites entering long-term stewardship are Uranium Mill Tailings Radiation Control Act Title I and Title II, Formerly Utilized Site Remedial Action Program, Department of Energy Decontamination and Decommission, Nuclear Waste Policy Act of 1982, Comprehensive Environmental Response, Compensation, and Liability Act of 1982, and Resource Conservation and Recovery Act of 1976. Although the Formerly Utilized Site Remedial Action Program is a program, not a law or policy, it was chosen as a category because of the numerous Formerly Utilized Site Remedial Action Program sites scheduled to enter long-term stewardship.

The review categorized requirements within those site types for each of the Science and Technology Roadmap Working Group Areas: safety systems and institutional controls, monitoring and sensors, contamination containment and control, and decision making and institutional performance. These groups are further subcategorized as shown in Figure 1. Information technology is a crosscutting subcategory applicable to all the Science and Technology Roadmap Working Group Areas.

The primary regulations for site types were used as a basis to narrow the requirements search. From these primary regulations the applicable national-level science and technology requirements for these subcategories were identified for each site type. Table 1 shows the primary regulations for the site types.

\section{REQUIREMENTS}

Numerous requirements for long-term stewardship with respect to long-term science and technology were identified from the review of the primary regulations listed in Table 1 for each subcategory. Because of the numbers of requirements identified, listing them all for each subcategory would be too lengthy for this paper. For the sake of brevity, only the requirement summaries for Information Technology and Safety Systems and Institutional Controls are presented. In addition, requirements for Formerly Utilized Site Remedial Action Program and Comprehensive Environmental Response, Compensation, and Liability Act sites were combined since they both have the same primary regulation. Similarly, requirements for Department of Energy Decontamination and Decommission and Nuclear Waste Policy Act site types were combined for the same reason.

\section{III.A. Information Technology}

Information technology has three subcategories, which are science and technology in nature: (1) record retention, (2) accessibility, and (3) media storage. Requirement detail for the site types varies. For some site types requirements for each of the three subcategories are identified and discussed. For other site types the subcategory requirements are more general and are therefore presented in a more general overview.

\section{III.A.1. Uranium Mill Tailings Radiation Control Act Title I and II Sites}

Code of Federal Regulations 10 CFR 40.27 and 10 CFR 40.28, primary regulations for Uranium Mill Tailings Radiation Control Act Title I and II, respectively, do not have any specific requirements or references to information technology. However, $10 \mathrm{CFR}$ 40.27 and 10 CFR 40.28 do require a description of the long-term surveillance program record keeping procedures as part of the license. Since the requirements for record keeping procedures are not explicitly provided, this implies that record keeping procedures are site specific in accordance to the license. Thus, each site could have different records, formats, and storage and retrieval methods. 


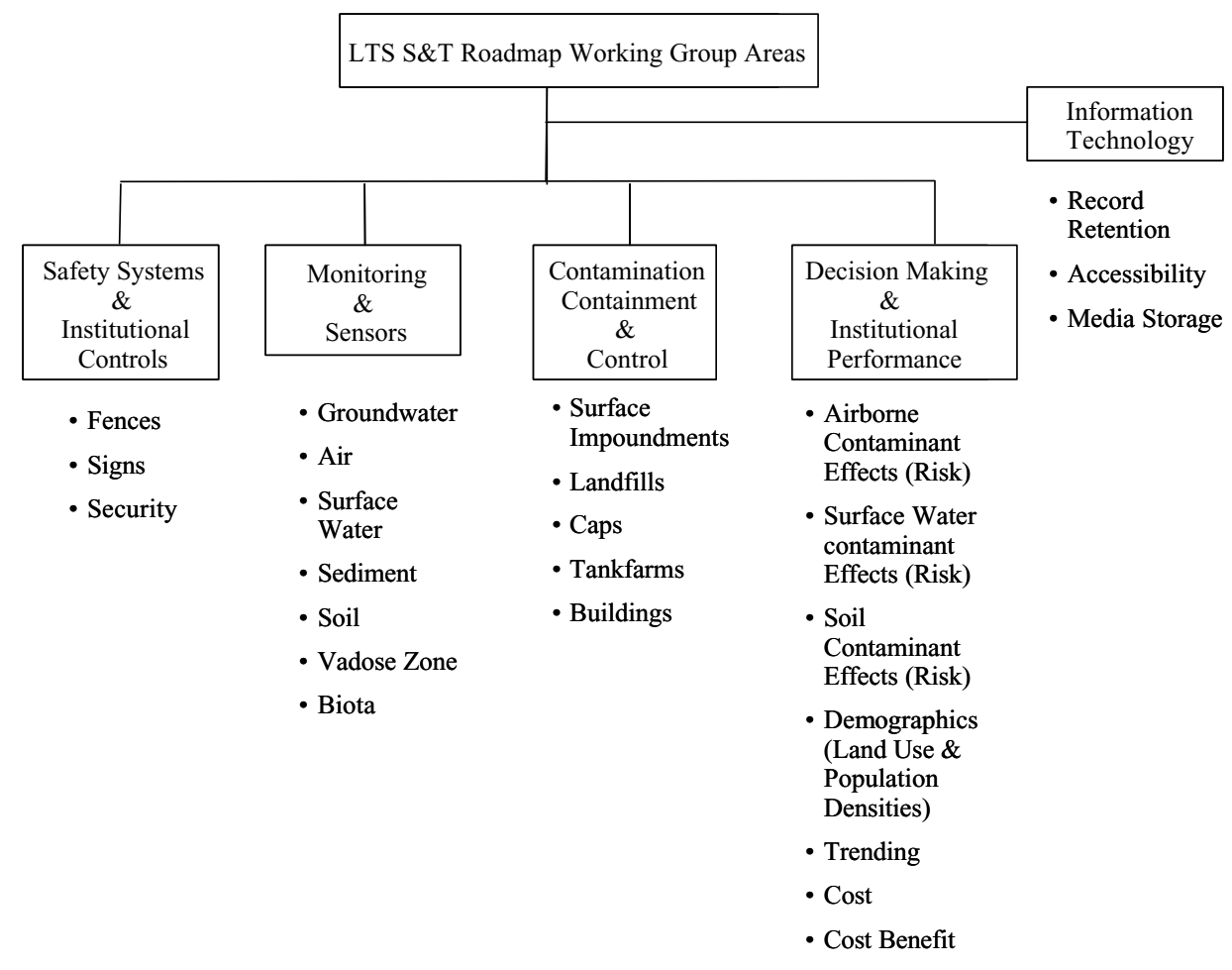

Figure 1. The Long-Term Stewardship Science and Technology Roadmap Working Group Areas were subcategorized.

Table 1. Site Type Primary Regulations.

\section{Site Type}

Uranium Mill Tailings Radiation Control Act Title I

Uranium Mill Tailings Radiation Control Act Title II

Nuclear Waste Policy Act of 1982

Formerly Utilized Site Remedial Action Program

Department of Energy Decontamination and Decommission

Comprehensive Environmental Response, Compensation, and Liability Act (CERCLA)
Primary Regulation

40 CFR 192 and

10 CFR 40.27

40 CFR 192 and

10 CFR 40.28

Department of Energy

Orders

CERCLA (40 CFR 300-399)

Department of Energy

Orders

CERCLA (40 CFR 300-399)

RCRA (40 CFR 260-299) 


\section{III.A.2. Department of Energy Decontamination and Decommission Site Types and Nuclear Waste Policy Act Sites}

Department of Energy Decontamination and Decommission and Nuclear Waste Policy Act sites' primary regulations are Department of Energy Orders. The applicable Department of Energy Order for information technology is Department of Energy Order 200.1, "Information Management Program." Department of Energy Order 200.1 has two requirements:

1. Information, information resources, and information technologies shall be managed in a manner that supports the strategic and operational plans of the Department.

2. Information management activities shall be established, maintained, and managed in a manner that addresses Department policy and implements appropriate laws and regulations as specified in Attachment II, References.

Attachment II, References, of Department of Energy Order 200.1 contains a list of 23 references. Each reference was reviewed for applicability to the appropriate subcategory for information technology. Of the 23 references reviewed, reference 6 of Department of Energy Order 200.1, 36 CFR 1200, was the most appropriate regulation for the category of information technology and its subcategories. For record retention $36 \mathrm{CFR} 1228.64$ requires records be transferred to the National Archives after 30 years unless the Department of Energy Secretary certifies the records must be retained for a longer period. For environmental records this has been done. The Department of Energy Environmental Record Schedule has requirements for record retention which are specific to the type of record being retained.

Accessibility of records is not explicitly stated with the exception of 36 CFR 1236, "Management of Vital Records." Vital records are required to be accessible in the event of an emergency. Vital records are policies, plans, and procedures developed and implemented and the resources needed to identify, use, and protect the essential records needed to meet operational responsibilities under national security emergencies or other emergency or disaster conditions, or to protect the Government's rights or those of its citizens.

Because most records for long-term stewardship will eventually be transferred to the National
Archives or stored in a similar manner, 36 CFR 1200 defines how to store the record type or media and formats acceptable by the National Archives. Media storage is specific to the type of media used.

\section{III.A.3. RCRA Sites}

Review of RCRA for information technology did not reveal requirements for long-term stewardship. However, RCRA requires a closure plan when a site is closed under RCRA. The specifics of record keeping for a RCRA site will likely be noted in the closure plan. Closure of underground storage tanks under RCRA is an exception. 40 CFR 280, Subpart $\mathrm{G}$, requires records for underground storage tanks to be maintained for at least three years after completion of permanent closure or change-in-service.

\section{III.A.4. Formerly Utilized Site Remedial Action Program and CERCLA Sites}

With respect to information technology CERCLA 40 CFR 300, Subpart I requires an administrative record be established at facilities undergoing response actions. 40 CFR 300 is specific as to when the administrative record must be established, but does not state how long nor what documents generated after the response action is completed that must be maintained in the administrative record. CERCLA requires the administrative record be kept at or near the facility where the response action is occurring. It also must be maintained at a central location, and to ensure public access to the administrative record, it cannot be located in an area where a security clearance is required. If wastes remain onsite after response action has been completed, CERCLA requires a fiveyear review. Supporting documents (i.e., monitoring data collected during the five-year period) would be necessary information to be maintained to support a CERCLA five-year review.

\section{III.B. Safety Systems and Institutional Controls}

Safety systems and institutional controls have three subcategories as identified for long-term stewardship with respect to science and technology: fences, signs, and security. Note that other subcategories for institutional controls include such things as liens and mineral rights, but they would not be improved by science or technology methods. Because the requirements identified for safety systems and institutional controls are not specific for each subcategory, the requirements for each site type are discussed in a general manner. 


\section{III.B.1. Uranium Mill Tailings Radiation Control Act Title I and II Sites}

The primary regulations for Uranium Mill Tailings Radiation Control Act Title I and II, 10 CFR 40.27 and 10 CFR 40.28, respectively, do not have requirements for fences, signs, or security. However, 10 CFR 61.42 also applies and requires the facility to ensure protection of any individual from inadvertently intruding into the disposal site and occupying the site or contacting the waste. This requirement does not specifically state to install a fence or signs, or to have a security system, but it implies the need for some types of safety system to prevent individuals from inadvertently intruding into a disposal site.

\section{III.B.2. Department of Energy Decontamination and Decommission Site Types and Nuclear Waste Policy Act Sites}

The Department of Energy has an order requiring protection of property. Department of Energy Order 5632.1.C-1, "Manual for Protection and Controls of Safeguards and Security," requires protection of government-owned property from damage, destruction, or theft. In addition to protection of property, this order protects human health and the environment from inadvertent entry.

\section{III.B.3. RCRA Sites}

RCRA, 40 CFR 264.117 and 40 CFR 265.117, state the Regional Administrator may require the same security as required during operations of the facility if the hazardous waste remains exposed after closure or access by the public or domestic livestock may pose a hazard to human health. Sites would meet these requirements in various ways and could use fences, signs, or other methods. 40 CFR 265.14 (c) specifically requires signs to be posted.

\section{III.B.4. Formerly Utilized Site Remedial Action Program and CERCLA Sites}

CERCLA does not have any requirements specific to signs, fences, or security. Instead, institutional controls are considered a response action under CERCLA and are part of a remedy. Institutional controls must meet all statutory requirements and are subject to the nine evaluation criteria outlined in 40 CFR 300.430. Thus, the need for signs, fences, or security would be addressed as part of the Record of Decision.

\section{GAPS AND CONFLICTS}

Gaps and conflicts exist for information technology and for safety systems and institutional controls. Some of the gaps and conflicts are science and technology in nature, while others are basic gaps and conflicts that need to be addressed.

\section{IV.A. Information Technology Gaps and Conflicts}

There is no policy or guidance that specifically addresses management of long-term stewardship information per se, including records. Thus there are multiple gaps, including:

- Identification of long-term stewardship records and information.

- $\quad$ Revised required retention for those records and information. Current retention schedules may not support long-term stewardship (e.g., well abandonment files are destroyed three years after plugging and abandonment).

- When, how, and where stewardship information (including records) is turned over post closure.

- What format stewardship information (including records) should be received and stored and how will it be updated over hundreds to thousands of years.

- Who will be responsible to manage the stewardship information (including records).

- $\quad$ A designated storage location for stewardship information (including records).

- $\quad$ How stewardship information (including records) will be preserved over a long period of time (potentially hundreds and even thousands of years).

- $\quad$ A consistent method of indexing stewardship information (including records) to ensure retrievability.

- $\quad$ Post-closure generation, turnover, and storage of stewardship information (including records).

- Who will finance stewardship information (including records) management and when (some media are already outdated). 
- $\quad$ How will contaminated stewardship information (including records) be handled.

- $\quad$ How will classified, sensitive, and proprietary information (including records) be handled.

- Who will have access to stewardship information and how classification of that information (including records) may affect that access.

- National Archives role in regards to stewardship records.

Because of the lack of policy and guidance in this area, the various sites are planning for stewardship of their information (and records) in various ways, leading to inconsistencies, inefficiencies, and potentially lacking important information.

\section{IV.B. Safety Systems and Institutional Controls Gaps and Conflicts}

The most significant gap for safety systems and institutional controls is the lack of specific policy or requirements for sites in long-term stewardship. One gap in institutional controls is at CERCLA sites. The Environmental Protection Agency imposed institutional controls at CERCLA sites via enforcement tools that only bind the parties named in the enforcement document. Thus, it may be necessary to develop policy that requires the parties to implement institutional controls that are applied to the property itself, independent of ownership.

Many safety systems and institutional controls requirements are addressed as site specific. In review of the requirements for safety systems and institutional controls, two conflicts were identified between the Environmental Protection Agency and the Department of Energy:

- $\quad$ Difference in regards to safety systems

- Definition of institutional controls.

As noted, the Environmental Protection Agency, RCRA, requires security if the hazardous waste remains exposed after closure or access by the public or domestic livestock may pose a hazard to human health. The Department of Energy requires protection (security) of government-owned property from damage, destruction, or theft. Although both requirements accomplish similar outcomes, the reasons for providing security are different.

The Environmental Protection Agency and the Department of Energy each have definitions for institutional controls. The Environmental Protection Agency, "Institutional Controls: A Site Manager's Guide to Identifying, Evaluating and Selecting Institutional Controls at Superfund and RCRA Corrective Action Cleanups," EPA 540-F-00-005, September 2000, defines institutional controls:

- $\quad$ Are non-engineered instruments such as administrative and/or legal controls that minimize the potential for human exposure to contamination by limiting land or resource use;

- Are generally to be used in conjunction with, rather than in lieu of, engineering measures such as waste treatment or containment;

- $\quad$ Can be used during all stages of the cleanup process to accomplish various cleanup-related objectives; and

- $\quad$ Should be "layered" (i.e., use multiple institutional controls) or implemented in series to provide overlapping assurances of protection from contamination.

The document specifically states that the Environmental Protection Agency does not consider physical barriers as institutional controls, which includes fences.

The Department of Energy, "Institutional Controls in RCRA and CERCLA Response Action," DOE/EH-413-0004, August 2000, states that institutional controls can include physical barriers (fences) and legal and communication devices (deed restrictions, zoning, and signs). Although both definitions have similarities they do have some distinct differences.

\section{CONCLUSION}

The science and technology requirements identification work is in progress and is scheduled to be completed by August 2002. The national science and technology requirements for each of the subcategories for the various site types will be presented. The science and technology requirements will be used by the Long-Term Stewardship Science and Technology Roadmap team as the roadmap 
matures to provide a framework to evaluate

technologies for development and to provide specific objectives for technology development.

In addition, gaps and conflicts will be presented. The gaps and conflicts identified for science and technology through this work provide the foundation for developing a policy and guidance strategy for long-term stewardship science and technology requirements.

The Department of Energy may need to develop new policy and guidance relative to Long-Term Stewardship Science and Technology to ensure protection of human health and the environment. The potentially new requirements may adopt many existing laws and address conflicts and gaps. To date, significant gaps in requirements have been identified. Specific science and technology requirements exist for active or operating sites, but few exist for closed sites with the exception of Uranium Mill Tailings Radiation Control Act Title I and II Sites. One strategy for development of policy is to ensure that no matter what regulations the site is closed under, if the site is to enter the Department of Energy Long-Term Stewardship National Program, one set of requirements could be established for postclosure stewardship operations. This would ensure consistency across the complex. 